\title{
The Dark Side of the Light Show: Predators of Fireflies in the Great Smoky Mountains
}

\author{
Sara M. Lewis, ${ }^{1}$ Lynn Faust, ${ }^{2}$ and Raphaël De Cock $^{3}$ \\ ${ }^{1}$ Department of Biology, Tufts University, Medford, MA 02155, USA \\ ${ }^{2}$ Emory River Land Company, 11828 Couch Mill Road, Knoxville, TN 37932, USA
}

${ }^{3}$ Evolutionary Ecology Group, University of Antwerp, 2610 Antwerp, Belgium

Correspondence should be addressed to Sara M. Lewis, sara.lewis@tufts.edu

Received 14 July 2011; Accepted 15 September 2011

Academic Editor: Diana E. Wheeler

Copyright (C) 2012 Sara M. Lewis et al. This is an open access article distributed under the Creative Commons Attribution License, which permits unrestricted use, distribution, and reproduction in any medium, provided the original work is properly cited.

\begin{abstract}
In the Great Smoky Mountains of East Tennessee, the Light Show is a popular seasonal attraction created by thousands of courting male Photinus carolinus fireflies (Coleoptera: Lampyridae) that flash in synchrony to locate females. This study was undertaken to provide a temporal snapshot of whether invertebrate predators are active within these dense and conspicuous firefly breeding aggregations. In addition, we examined whether female Photuris fireflies, which are specialist predators on other fireflies, show any feeding preferences within the diverse local firefly fauna. A field survey revealed a surprisingly diverse suite of generalist insectivores feeding on fireflies within P. carolinus breeding aggregations. In addition, laboratory studies revealed major differences in prey consumption rates when Photuris predators were given access to several lampyrid taxa. This suite of generalist and specialist predators appears to create a complex selective landscape that is predicted to be a powerful force shaping the evolution of firefly defenses.
\end{abstract}

\section{Introduction}

Animals with conspicuous courtship displays that breed in dense aggregations are expected to be targeted by many predators [1, 2]. Fireflies (Coleoptera: Lampyridae), however, have a reputation for being distasteful to many potential predators $[3,4]$. Several lampyrid taxa have been shown to contain chemicals that confer protection against generalist insectivores such as birds, spiders, and ants [5-7]. While lists have published tallying instances of observed predation on various fireflies $[3,8]$, no study has described the predator guild active within a firefly breeding aggregation at a single location and season.

In North America, Photuris fireflies are specialist predators that eavesdrop on the courtship signals of other fireflies [9-12]. Photuris females have been shown to be voracious predators of certain Photinus fireflies [3, 13, 14], from which they sequester defensive compounds known as lucibufagins [6]. Lloyd $[3,10]$ reviewed numerous field observations of Photuris females preying upon several firefly species. Eisner et al. [6] reported lab studies in which 6 Photuris females each ate 2 Photinus ignitus males, and a study by Gronquist et al. [15] found that 5 Photuris females each ate 3 Lucidota atra fireflies, a diurnally active species that also contains lucibufagins. To date, however, no systematic study has been made of the feeding proclivities of these predatory Photuris fireflies.

The Great Smoky Mountains in East Tennessee host a diverse and abundant lampyrid fauna, including both diurnal and nocturnal species $[16,17]$. Among these are Photinus carolinus, a species in which thousands of males gather in dense aggregations and flash synchronously to locate females $[18,19]$. In the Great Smoky Mountains National Park (GSMNP), this phenomenon is popularly known as the Light Show. During their 2-week mating season in June, these fireflies attract close to 30,000 park visitors. Such aggregations might be expected to attract many predators as well. Faust [19] reported that $P$. carolinus males were often caught in webs of Araneidae spiders, and harvestmen (Opiliones: Phalangiidae) was found carrying dead P. carolinus.

Another abundant nocturnal firefly, Phausis reticulata, is also active in this rich alluvial montane habitat at the same time of night. Commonly known as blue ghost fireflies, these males fly slowly over the forest floor emitting a bluegreen flickering glow. However, to date there has been no systematic survey describing the common predators of these two firefly species which are so popular with park visitors. 
This study was conducted during the $P$. carolinus mating season with the goal to survey invertebrate predators of $P$. carolinus and Phausis reticulata adults and also to determine whether specialist Photuris predators differentially prey on various firefly taxa.

\section{Methods}

2.1. Field Surveys of Firefly Predators. Field observations were conducted at GSMNP by walking along a $\sim 4 \mathrm{~km}$ path through P. carolinus breeding aggregations from 2000 to $2400 \mathrm{~h}$ during the peak display season (4-19 June 2011). Our surveys were conducted in Sevier Co. at Elkmont, Tennessee $\left(35^{\circ} 39^{\prime} 13^{\prime \prime} \mathrm{N}, 83^{\circ} 34^{\prime} 50^{\prime \prime} \mathrm{W}\right)$, although this species is found throughout the park in second growth hardwood forests at about $750 \mathrm{~m}$ elevation [19]. Male courtship signals in $P$. carolinus consist of flash trains containing 4-8 pulses given at $0.5 \mathrm{sec}$ intervals, followed by $6-9 \mathrm{sec}$ of darkness; females respond to male advertisements by emitting a doublet flash approximately $3 \mathrm{sec}$ following final pulse in a male's flash train [19]. We detected predation by looking along the ground and on vegetation for the distress flashes given by $P$. carolinus; these distress flashes consist of consistent, rhythmic single flashes repeated every $1.5-3 \mathrm{sec}$ [19] and are easily distinguished from firefly courtship flashes. We also looked for continuous stationary glows emitted from the light organ of injured fireflies. Whenever predatorprey interactions were observed, they were recorded and photographed (Sony Cybershot DSC-T20). Prey captured by orb-weaving spiders was monitored by counting firefly and other captured prey nightly in webs at $\sim 2400 \mathrm{~h}$, toward the end of the P. carolinus flight period. Since webs were less likely to contain glowing prey towards the end of the firefly season, web surveys were made with spotlights.

Similar observations focusing on invertebrate predators of nocturnal fireflies were also made in other areas of GSMNP. Birds and other potential diurnal predators were not covered by our surveys, as nocturnal fireflies such as $P$. carolinus disperse during the day to rest on or under vegetation, and thus their interactions with diurnal predators are quite difficult to observe. Similarly, it was logistically impossible to include bat predators in our field survey.

2.2. Laboratory Tests of Photuris Feeding Preferences. While most adult fireflies do not feed, some Photuris females are specialist nocturnal predators that hunt Photinus males using a combination of stalking, aerial hawking, and aggressive mimicry of prey females $[9,10,13,20]$. To determine whether predaceous Photuris females show preferences among males of different lampyrid taxa, we conducted laboratory trials using as prey several different firefly species that overlapped spatially and/or temporally with Photuris spp. Because Photuris is a taxonomically problematic group currently in need of revision, it is not possible to provide definitive species identifications for these predators. These females included Photuris hebes and P. lucicrescens, while others were in the Photuris versicolor complex (J. E. Lloyd, personal communication): here we refer to them collectively as Photuris.
All fireflies were kept on a 14 : 10 light cycle (this was shifted from natural by $9 \mathrm{~h}$ ). Predatory Photuris females were housed individually in 1 -quart $(14 \mathrm{~cm}$ height $\times 10 \mathrm{~cm}$ diameter) plastic containers with damp paper towel and a silk plant, and prey was added at dusk. Because prey could move about and avoid attacks, this experimental setup provided considerably more natural conditions than the $9 \mathrm{~cm}$ petri dishes assays that have previously been used in lab studies of Photuris predation $[6,15]$. Photuris behavior was observed for the first hour under blue light (many lampyrids show reduced retinal sensitivity for these wavelengths [21]), and trials were checked periodically for $24 \mathrm{~h}$. These laboratory trials were conducted between 6 and 21 June 2011. Most prey was offered in pair-choice trials, which allowed us to test several species during their short breeding seasons. Some prey was offered in single-choice trials: 4 (of 8) Phausis reticulata, and 8 (of 40) Photinus pyralis.

Because they are lampyrid specialists, none of the 11 Photuris females we tested consumed any of the "palatable" prey we offered them in these experiments (these included Tribolium beetle larvae, as well as various flies, click beetles, grasshoppers, and bugs that were collected from the field). We therefore confirmed that Photuris predators were hungry, following trials in which no prey was eaten, by offering them prey shown to be highly desirable (P. carolinus or L. atra) in our preliminary experiments.

\section{Results}

3.1. Field Surveys of Nocturnal Firefly Predators. Several predators were found actively hunting in the midst of $P$. carolinus mating aggregations (Figure 1). Orb-weaving spiders including Cyclosa conica (Figure 1(a)) and Neoscona arabesca constructed webs at dusk that captured mainly P. carolinus males, which constituted $72 \%$ of prey items; on a single night one web contained 7 P. carolinus males. In addition, 2 Phausis reticulata males (blue ghost fireflies) along with 1 P. carolinus female were found trapped in webs. Thus, of the 25 total prey items found in these webs, the vast majority were male fireflies. Many of the males continued to flash rhythmically after they were wrapped in silk. We also noticed that fireflies were often positioned at the center of spider webs, although we did not quantify how often this occurred.

Remains were collected the next morning below marked web locations, and these silk-wrapped fragments suggested active predation on $P$. carolinus by orb-weavers. Some $P$. carolinus males had been partially consumed, while others were largely intact but had a large puncture wound at the anterior corner of their wing cover.

Additional predators included several Leiobunum spp. harvestmen (Opiliones: Phalangiidae) that we observed feeding on P. carolinus males. One had captured a newly eclosed Photuris which struggled unsuccessfully to escape (Figure 1(b)). In addition to preying on live fireflies, harvestmen were also observed feeding on silk-wrapped fireflies that they apparently scavenged from beneath the webs of orbweaving spiders. An assassin bug, Zelus luridus (Hemiptera: Reduvidae), was found perched on a hickory tree leaf $\sim 10 \mathrm{ft}$ off the ground, feeding on a $P$. carolinus male that 


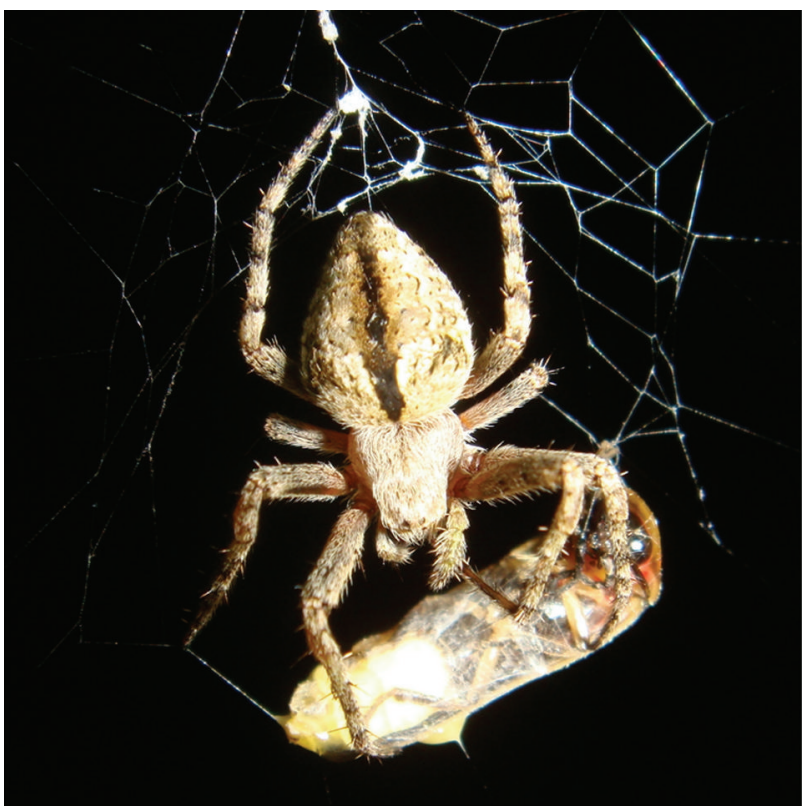

(a)

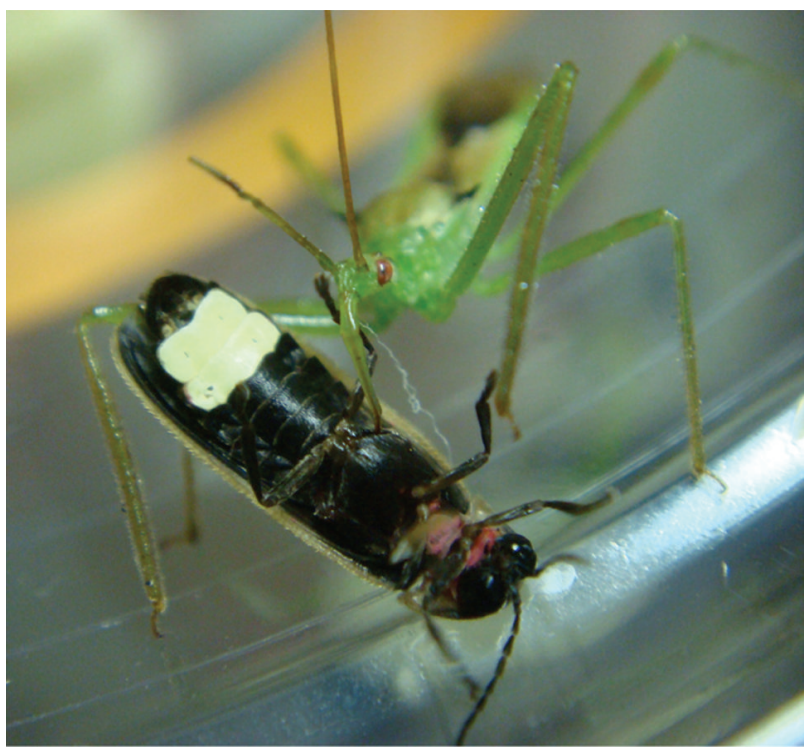

(c)

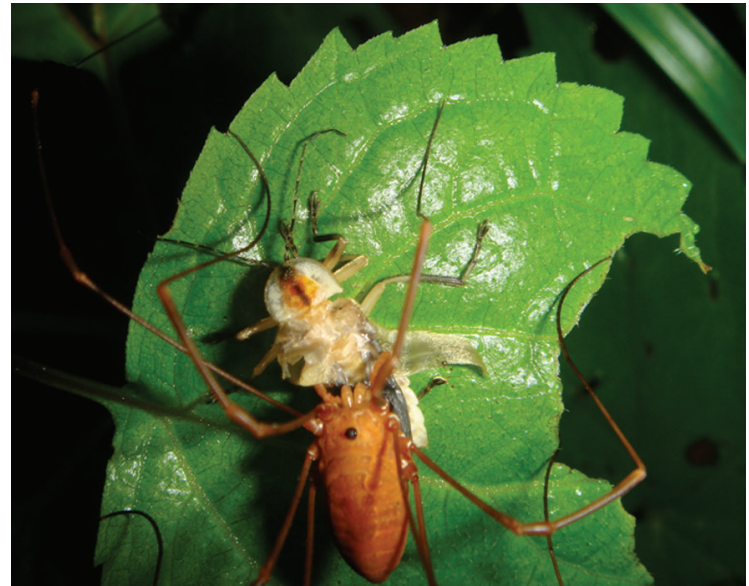

(b)

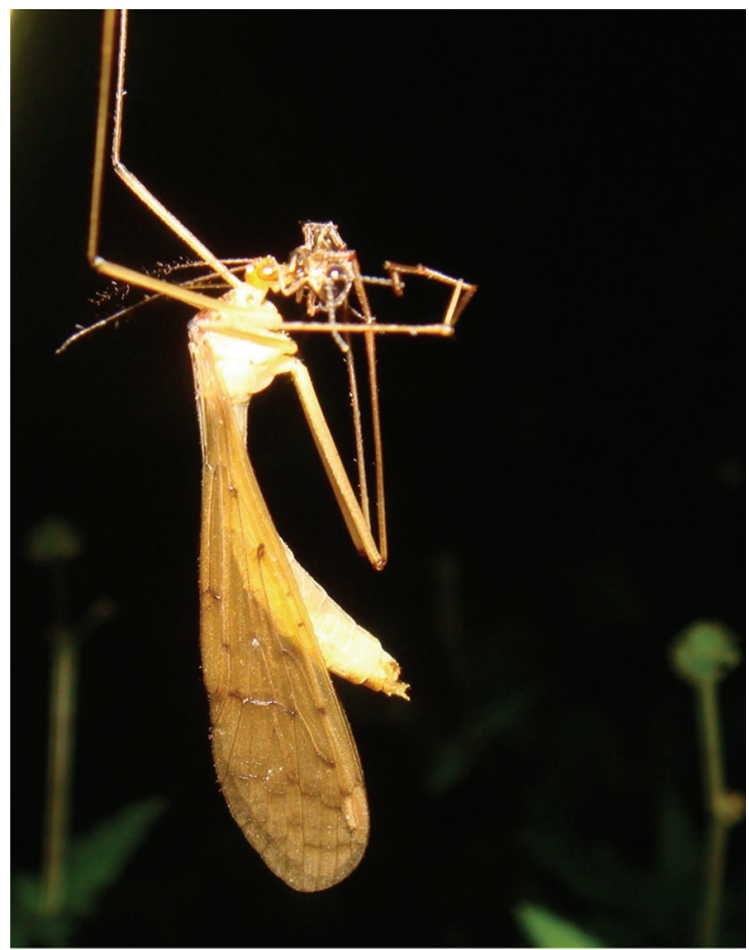

(d)

Figure 1: Some invertebrate predators of fireflies in the Great Smoky Mountains (photos by R. De Cock). (a) Orb-weaving spider (Araneidae) Cyclosa conica attacking a Photinus male that has been caught and wrapped. (b) Harvestman Leiobunum spp. (Opiliones: Phalangiidae) attacking a newly eclosed Photuris firefly. (c) Zelus luridus assassin bug (Hemiptera: Reduviidae) feeding on a male Photinus carolinus. (d) Bittacus spp. hangingfly (Mecoptera: Bittacidae) consuming a male Phausis reticulata.

was flashing periodically. When brought into the lab, this bug recommenced feeding on the same $P$. carolinus male by piercing the intersegmental membrane between the fireflies' thorax and abdomen with its proboscis (Figure 1(d)). Two small Theridion spp. cobweb spiders were each found eating a Phausis male wrapped in silk. In addition, two Bittacus spp. hangingflies (Mecoptera: Bittacidae) were each found consuming still-glowing Phausis males (Figure 1(d)).

When we surveyed four webs at the end of the P. carolinus flight season, we found only a single nonfirefly prey item at the study site. However, two webs were found nearby that each contained a single firefly (one web captured a P. carolinus male and the other a Phausis reticulata male). Thus, web capture efficiency appeared to be dependent on firefly population density, with fewer captures as firefly abundance declined.

3.2. Laboratory Tests of Photuris Feeding Preferences. All Photuris females fed readily under these experimental conditions (Figures 2(a) and 2(b)); one predator consumed 8 out the 11 


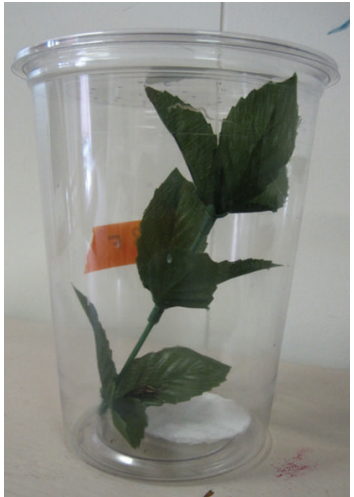

(a)

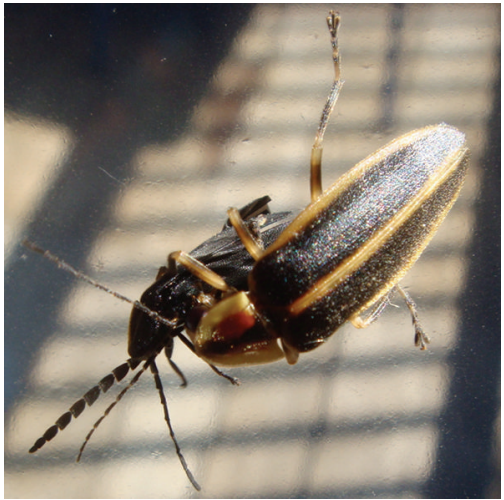

(b)

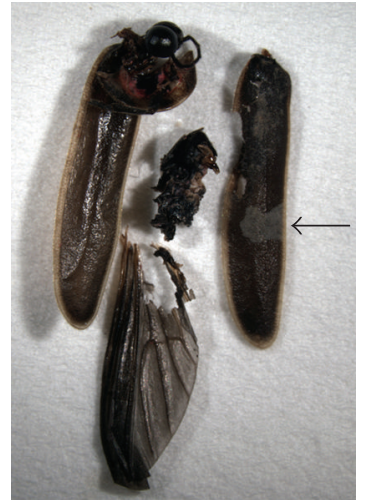

(c)

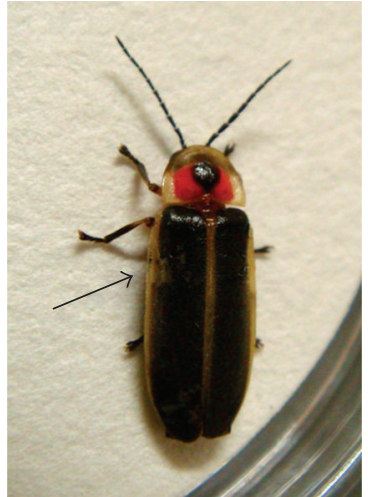

(d)

Figure 2: Laboratory tests of Photuris feeding preferences choice. (a) Trial setup with single Photuris spp. female in 1-quart container with artificial plant. (b) Female Photuris attacking an L. atra firefly. (c) Remnants of a male Photinus carolinus (arrow indicates dried hemolymph on the elytra). (d) A surviving male Photinus pyralis (arrow indicates puncture wound on left elytra).

prey she was offered over 7 days of testing. During the light photoperiod both predators and prey generally rested on the upper or lower surface of artificial leaves or sides of the container. Within $1 \mathrm{hr}$ of dark phase, fireflies started walking, flashing, and occasionally flying. When prey fireflies were contacted by the Photuris female, they rapidly withdrew or dropped to the bottom of the container. During a predator attack, the Photuris female grasped the firefly with her front legs and then bit into the prey, often between the elytral shoulder and the pronotum, with her mandibles. Prey reflex bleeding (originally described by Blum and Sannasi [22] for Photinus pyralis) was often observed. When they were bitten, both $P$. pyralis and $P$. carolinus males released copious amounts of thick white fluid; we often observed that this fluid rapidly coagulated into a sticky mass that coated the predator's mouthparts. Although this appeared to temporarily prevent the Photuris female from continuing her attack, under laboratory conditions most predators eventually returned to continue feeding on the wounded prey. Notably, Phausis reticulata males did not exhibit reflex bleeding although they typically showed prolonged thanatosis. After 24 hours, prey that had been successfully attacked had been reduced to scattered bits of exoskeleton, including pronotum, eyes, elytrae, and wings (Figure 2(c)).

We found marked differences in consumption rates when various firefly species were offered to captive Photuris females (Figure 3). In three Photinus species, P. carolinus, P. macdermotti, and P. marginellus, $60-76 \%$ of males were eaten within $24 \mathrm{~h}$; in contrast, only $12.5 \%$ of Photinus pyralis males were eaten. Microscopic examination of the surviving $P$. pyralis males revealed that many had been attacked, as bite marks and dried blood were seen on their pronotum or elytra (Figure 2(d)). Most Phausis reticulata also remained uneaten over $24 \mathrm{~h}$, although again close examination of the surviving males revealed bite marks on their elytra or abdomen. We also tested two diurnally active species of Lucidota fireflies, $L$. atra and L. punctata, both of which were readily consumed by Photuris females (Figure 3).

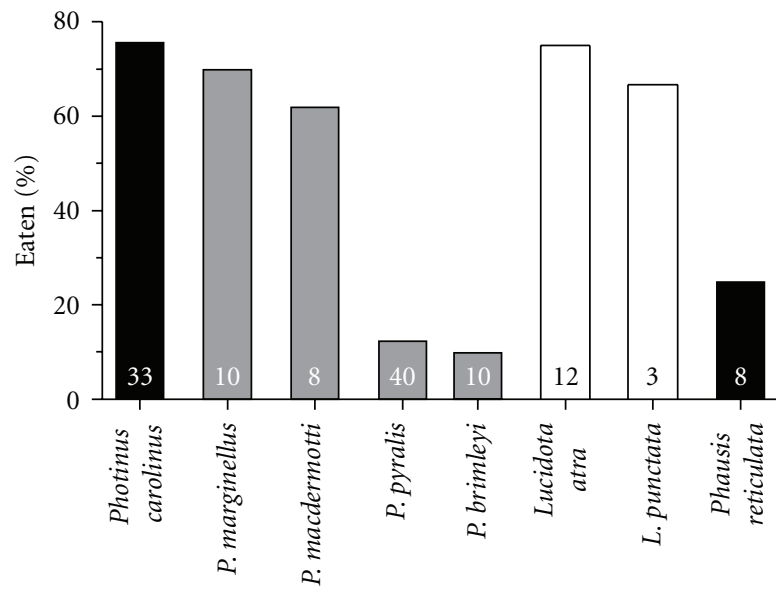

Prey species offered

FIGURE 3: Differences among firefly taxa in the percentage of individuals consumed by predatory Photuris femmes fatales during $24 \mathrm{~h}$ laboratory trials. Sample sizes (number of trials) are shown within bars, and shading indicates the activity period of each species (black: fully nocturnal; grey: dusk-active; white: diurnal).

We incidentally noted very few parasitoids among the fireflies collected for this study: about $5 \%$ of Photuris females appeared to die from tachinid parasitism (Strongygaster triangulifera Loew), and less than $5 \%$ of prey (all species combined) died due to phorids (Apocephalus antennatus Malloch).

\section{Discussion}

Previous reviews have described the general diversity of firefly predators $[3,4]$. Our study focused on providing a temporal snapshot of predation upon Smokies fireflies during the brief but explosive breeding season of the synchronous firefly, Photinus carolinus. Our field survey revealed a surprisingly diverse suite of predators feeding on fireflies 
within these aggregations, including the first record of hangingflies (Mecoptera) eating fireflies, here Phausis reticulata. Our results confirm that harvestmen are firefly predators as well as scavengers. This supports previous observations by Lloyd [3], who also noted that harvestmen (including Leiobunum) ate live fireflies (Photuris spp. and Photinus scintillans) on three occasions. It is not known whether these opilionid arachnids are able to visually detect lightemitting prey, but the capacity to orient toward light has been demonstrated for two cave-dwelling harvestmen that feed exclusively on the bioluminescent dipteran, Arachnocampa luminosa [23]. Our observation of predation on Photinus carolinus fireflies by the reduviid bug Zelus luridus confirms Lloyd's [3] reports of Zelus spp. attacking a female Photuris congener, and an unsuccessful attack by another reduviid on a male Pteroptyx firefly. Spiders and other invertebrates have also been reported to consume various Japanese fireflies [8]. It seems likely that such predators use a combination of substrate vibrations and visual cues to detect fireflies walking on leaf litter or vegetation, as shown for lycosid spiders [24].

Orb-weaving spiders are a notable source of male-biased mortality for fireflies, as they mainly capture flying males that are searching for females [3]. We found this to be especially true for the males of two fully nocturnal fireflies, $P$. carolinus and Phausis reticulata. While diurnal (Lucidota atra, L. punctata) and dusk-flying fireflies (Photinus macdermotti and $P$. marginellus) were also active at this site, these species were less susceptible to predation by nocturnal orb-weavers because their webs were constructed after dark and then dismantled before the next morning. Our field survey also supports previous observations that once fireflies are captured in a web, many continue to glow or flash rhythmically $[3,8,25]$. Previous authors have suggested that this behavior acts as a bioluminescent lure to attract additional prey to the web; so it would repay further investigation to determine whether and how spiders are able to induce their prey's bioluminescence. We also noticed that captured fireflies were quite often positioned at the center of webs, which might also serve to maximize a spider's chance of capturing additional prey that had been attracted.

Consumption of Photinus carolinus and Phausis reticulata by these diverse generalist predators remains somewhat surprising because firefly taxa have been shown to contain a variety of defensive steroidal pyrones collectively known as lucibufagins (LBGs). First isolated from Photinus ignitus and $P$. marginellus [5], LBGs have also been found in $P$. pyralis [26] and Lucidota atra [15], as well as in larvae of the European glow-worm, Lampyris noctiluca [27]. LBG deters predation by at least two generalist predators: Hylocichla thrushes [5] and Phidippus jumping spiders [6]. As Photinus carolinus and Phausis reticulata have not yet been examined, it is possible that these species lack chemical defenses. Alternatively, it may be that the suite of generalist predators active within these breeding aggregations is able to circumvent firefly chemical defenses.

Our lab results confirm previous field observations indicating that nocturnally active Photuris females are specialist predators upon other fireflies[9]. Eisner et al. [6] demon- strated that Photuris fireflies are incapable of producing LBG on their own but rather must rely on acquiring these compounds from their prey to gain protection against their own predators. Thus, we expect Photuris predation to select for very different defensive strategies than those that might be effective against generalist insectivores.

Although our results indicate that Photuris females readily consume a broad range of lampyrid prey, including males of the synchronous species Photinus carolinus, firefly taxa differed markedly in their susceptibility to predation by Photuris fireflies. What factors might account for such differences? It might be predicted that those prey species whose activity period overlaps with the fully nocturnal Photuris would show reduced susceptibility. However, observed Photuris predation rates did not follow this prediction: low consumption rates were seen for the fully nocturnal blue ghost firefly, Phausis reticulata, but also for two duskactive fireflies, Photinus pyralis and P. brimleyi. In addition, Photuris females readily consumed some dusk-active, some fully nocturnal, and two diurnal species.

Another reasonable prediction is that Photuris consumption rates might be positively correlated with LBG content across lampyrid taxa. Unfortunately, this cannot currently be tested because the defensive chemistry of most firefly taxa remains unexamined. However, two firefly species shown in our study to be highly palatable are known to contain LBG: Photinus marginellus [5] and Lucidota atra, [15]. Thus, these species and others such as the synchronous firefly Photinus carolinus could be especially targeted by Photuris predators that are seeking to obtain LBG.

Several explanations may be considered for the very low Photuris predation rates we observed on three firefly species. Many firefly taxa exhibit reflex bleeding when disturbed, emitting droplets of hemolymph from their elytra and pronotum [22]. The released hemolymph rapidly coagulates, and this lampyrid bloodbath has previously been shown to deter predation by ants $[7,8,22]$. Our observations indicate that reflex bleeding may also help some fireflies escape predation by Photuris females, as we observed predators that were incapitated when their mouthparts became coated by sticky, coagulated blood. Photinus pyralis males are presumably desirable prey as they contain LBG [26], and they might use such copious reflex bleeding to gain mechanical protection against Photuris predators. The same may be true for Photinus brimleyi, although its defensive chemistry is unknown. Strong selection is expected for a prey's ability to glue shut a predator's mouthparts, as under natural conditions this would almost certainly allow the prey to escape. An alternate explanation is that additional chemical deterrents, or different and perhaps less desirable forms of LBG [26], make these particular Photinus species less attractive as prey for Photuris. Finally, in spite of their lack of reflex bleeding, Phausis reticulata males were often attacked yet not eaten. This suggests that these blue ghost fireflies also may have additional chemical deterrents and/or may lack the particular LBG required by Photuris females.

In summary, this temporal snapshot of predators active within Smokies firefly aggregations has revealed a surprisingly diverse suite of generalist insectivores. In addition, 
laboratory studies in which specialist Photuris predators were given access to several lampyrid taxa revealed major differences in prey consumption rates. The predator-prey interactions described here suggest that the evolution of firefly defenses occurs within a complex selective landscape involving both generalist and specialist predators. Testing evolutionary hypotheses concerning firefly chemical defenses and their effectiveness against both types of predators should prove a powerful approach for future investigations.

\section{Additional Information}

See Supplementary Material available online at doi: 10.1155/ $2012 / 634027$. It is a short video that illustrates common predators on fireflies and shows attacks by predatory Photuris fireflies.

\section{Acknowledgments}

The authors are grateful to Dr. Susan Riechert for spider identifications and the U.S. National Park Service for permitting them to conduct this research within the Great Smoky Mountains National Park. They also thank Patti Edwards for her expert field assistance and logistical support, and Griff Sextet for providing musical accompaniment. They also thank Norman Woodley and Brian Brown for identifications of tachinids and phorids, respectively. R. De Cock was funded by a research grant from the Research Foundation Flanders (F.W.O. file K2.064.11N).

\section{References}

[1] T. Burk, "Evolutionary significance of predation on sexually signaling males," Florida Entomologist, vol. 65, no. 1, pp. 90-104, 1982.

[2] M. Zuk and G. R. Kolluru, "Exploitation of sexual signals by predators and parasitoids," Quarterly Review of Biology, vol. 73, no. 4, pp. 415-438, 1998.

[3] J. E. Lloyd, "Firefly parasites and predators," Coleopterists Bulletin, vol. 27, no. 2, pp. 91-106, 1973.

[4] J. C. Day, "Parasites, predators and defence of fireflies and glow-worms," Lampyrid, vol. 1, pp. 70-102, 2011.

[5] T. Eisner, D. F. Wiemer, L. W. Haynes, and J. Meinwald, "Lucibufagins: defensive steroids from the fireflies Photinus ignitus and P. marginellus (Coleoptera: Lampyridae)," Proceedings of the National Academy of Sciences of the United States of America, vol. 75, no. 2, pp. 905-908, 1978.

[6] T. Eisner, M. A. Goetz, D. E. Hill, S. R. Smedley, and J. Meinwald, "Firefly "femmes fatales" acquire defensive steroids (lucibufagins) from their firefly prey," Proceedings of the National Academy of Sciences of the United States of America, vol. 94, no. 18, pp. 9723-9728, 1997.

[7] X. Fu, O. Nobuyoshi, V. B. Meyer-Rochow, Y. Wang, and C. Lei, "Reflex-bleeding in the firefly Pyrocoelia pectoralis (Coleo-ptera: Lampyridae): morphological basis and possible function," Coleopterists Bulletin, vol. 60, no. 3, pp. 207-215, 2006.

[8] N. Ohba and T. Hidaka, "Reflex bleeding of fireflies and prey-predator relationship," Science Report of the Yokosuka City Museum, vol. 49, pp. 1-12, 2002.
[9] J. E. Lloyd, "Firefly mating ecology, selection and evolution," in The Evolution of Mating Systems in Insects and Arachnids, J. C. Choe and B. Crespi, Eds., pp. 184-192, Cambridge University Press, Cambridge, UK, 1997.

[10] J. E. Lloyd, "Occurrence of aggressive mimicry in fireflies," Florida Entomologist, vol. 67, no. 3, pp. 368-376, 1984.

[11] S. M. Lewis and C. K. Cratsley, "Flash signal evolution, mate choice, and predation in fireflies," Annual Review of Entomo$\log y$, vol. 53, pp. 293-321, 2008.

[12] W. A. Woods, H. Hendrickson, J. Mason, and S. M. Lewis, "Energy and predation costs of firefly courtship signals," American Naturalist, vol. 170, no. 5, pp. 702-708, 2007.

[13] J. E. Lloyd, "Aggressive mimicry in Photuris: firefly femmes fatales," Science, vol. 149, no. 3684, pp. 653-654, 1965.

[14] J. E. Lloyd, "Aggressive mimicry in Photuris fireflies: signal repertoires by femmes fatales," Science, vol. 187, no. 4175, pp. 453-453, 1975.

[15] M. Gronquist, F. C. Schroeder, H. Ghiradella et al., "Shunning the night to elude the hunter: diurnal fireflies and the "femmes fatales", Chemoecology, vol. 16, no. 1, pp. 39-43, 2006.

[16] A. Mayor, National Park Service. Great Smoky Mountains National Park. Gatlinburg, Tennessee. Discover Life in America, http://www.dlia.org/atbi/species/Animalia/Arthropoda/ Insecta/Coleoptera/Elateroidea.

[17] L. Faust and P. Weston, "Degree-day prediction of adult emergence of the firefly Photinus carolinus," Environmental Entomology, vol. 38, no. 5, pp. 1505-1512, 2009.

[18] J. Copeland and A. Moiseff, "The occurrence of synchrony in the North American firefly Photinus carolinus (Coleoptera: Lampyridae)," Journal of Insect Behavior, vol. 8, no. 3, pp. 381-394, 1995.

[19] L. F. Faust, "Natural history and flash repertoire of the synchronous firefly Photinus carolinus (Coleoptera: Lampyridae) in the Great Smoky Mountains National Park," Florida Entomologist, vol. 93, no. 2, pp. 208-217, 2010.

[20] J. E. Lloyd and S. R. Wing, "Nocturnal aerial predation of fireflies by light-seeking fireflies," Science, vol. 222, no. 4624, pp. 634-635, 1983.

[21] A. B. Lall, T. Cronin, E. J. H. Bechara, C. Costa, and V. R. Viviani, "Visual ecology of bioluminescent beetles: visual spectral mechanisms and the colors of optical signaling in Coleoptera, Elateroidea: Lampyridae, Elateridae and Phengodidae," in Bioluminescence in Focus - A Collection of Illuminating Essays, V. B. Meyer-Rochow, Ed., pp. 201-228, Research Signpost, Kerala, India, 2009.

[22] M. S. Blum and A. Sannasi, "Reflex bleeding in the lampyrid Photinus pyralis: defensive function," Journal of Insect Physio$\log y$, vol. 20, no. 3, pp. 451-460, 1974.

[23] V. B. Meyer-Rochow and A. R. Liddle, "Structure and function of the eyes of two species of opilionid from New Zealand glow-worm caves (Megalopsalis tumida: Palpatores, and Hendea myersi cavernicola: Laniatores)," Proceedings of the Royal Society B, vol. 233, no. 1272, pp. 293-319, 1988.

[24] R. S. Lizotte and J. S. Rovner, "Nocturnal capture of fireflies by lycosid spiders: visual versus vibratory stimuli," Animal Behaviour, vol. 36, no. 6, pp. 1809-1813, 1988.

[25] S. M. Lewis and O. Wang, "Reproductive ecology of two species of Photinus fireflies (Coleoptera: Lampyridae)," Psyche, vol. 98, no. 4, pp. 293-37, 1991. 
[26] J. Meinwald, D. F. Wiemer, and T. Eisner, "Lucibufagins. 2. Esters of 12-Oxo-2B,11A-trihydroxybufalin, the major defensive steroids of the firefly Photinus pyralis," Journal of the American Chemical Society, vol. 101, no. 11, pp. 3055-3060, 1979.

[27] J. Tyler, W. McKinnon, G. Lord, and P. Hilton, "A defensive steriodal pyrone in the glow-worm Lampyris noctiluca $\mathrm{L}$. (Coleoptera: Lampyridae)," Physiological Entomology, vol. 33, no. 2, pp. 167-170, 2008. 

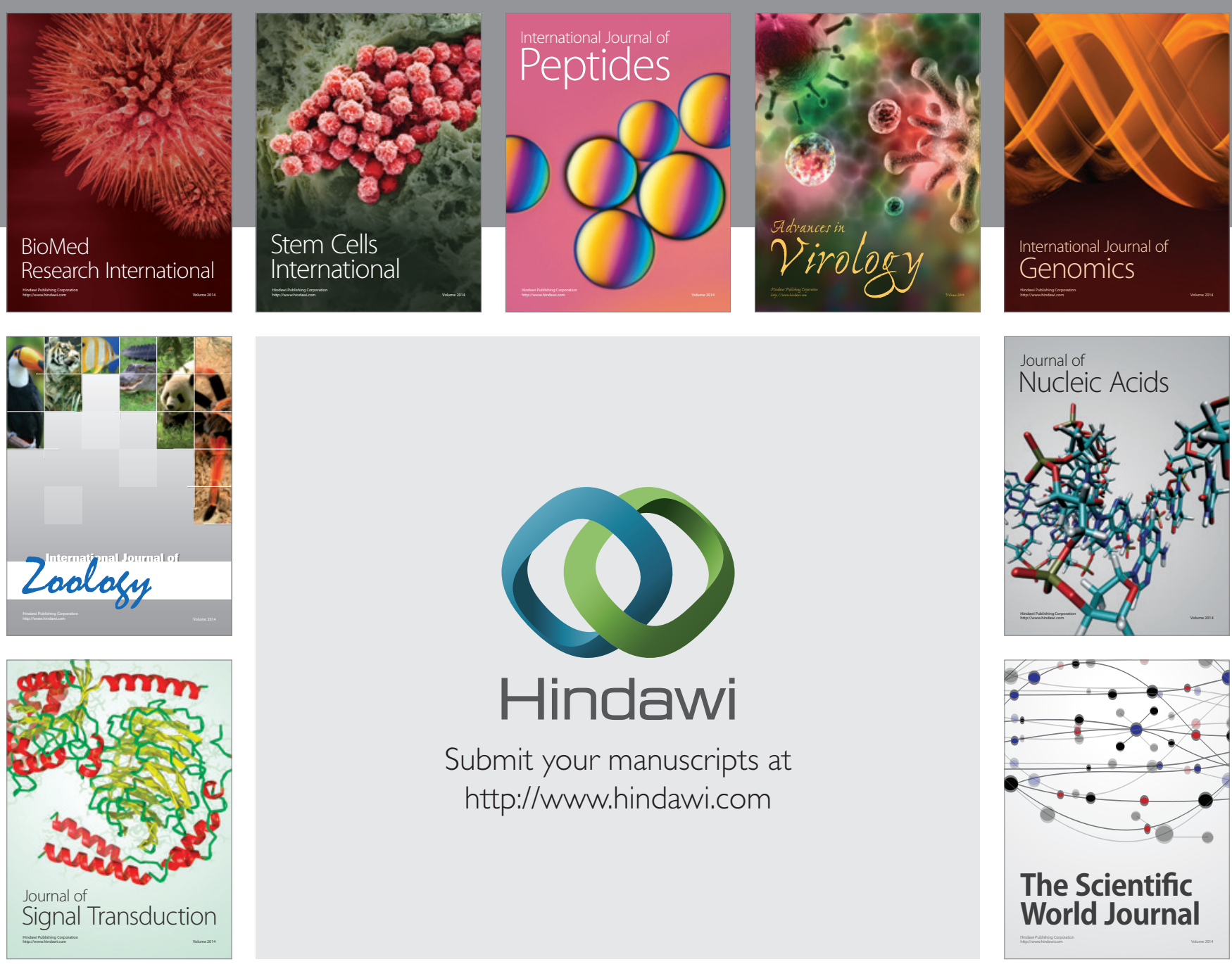

Submit your manuscripts at

http://www.hindawi.com
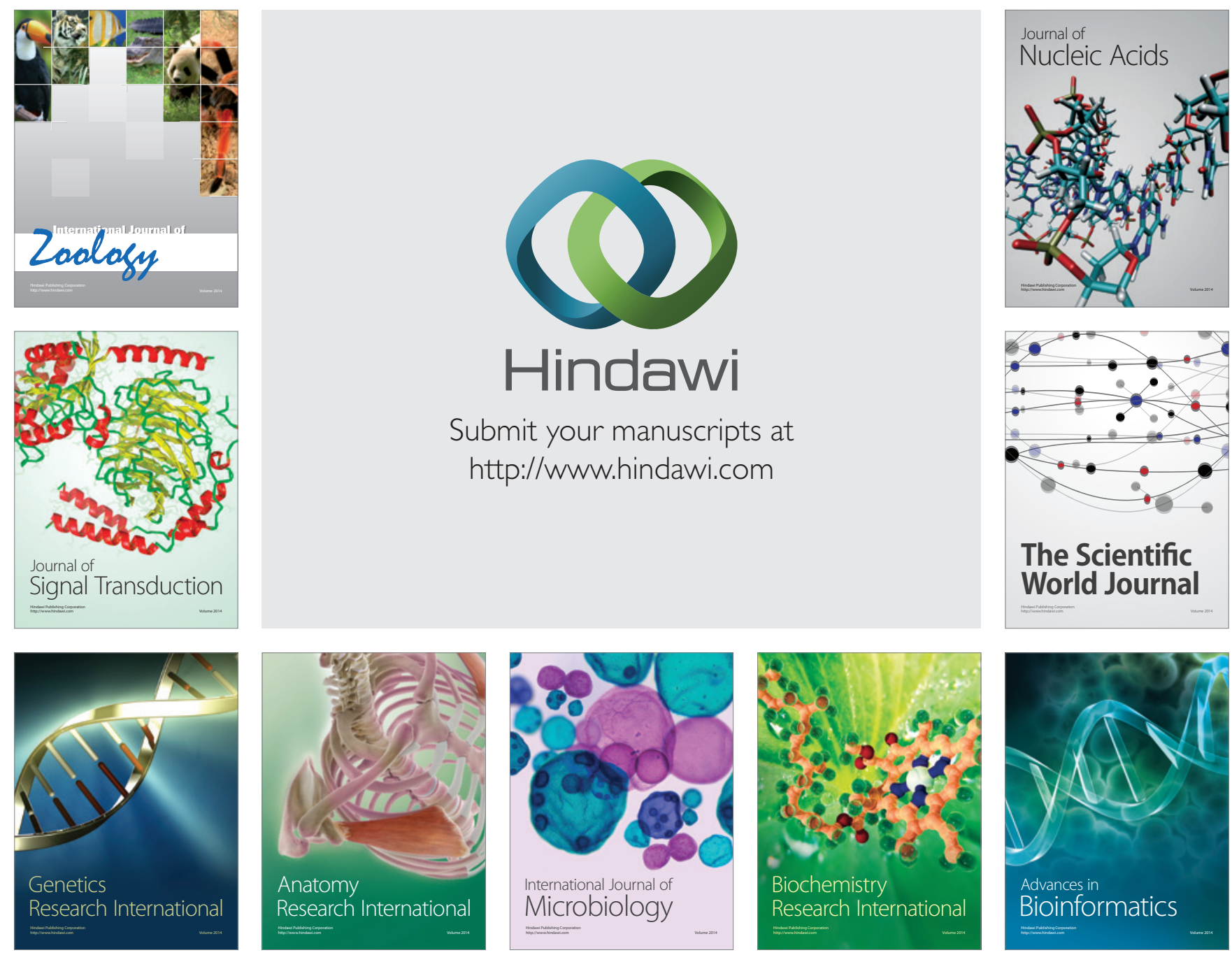

The Scientific World Journal
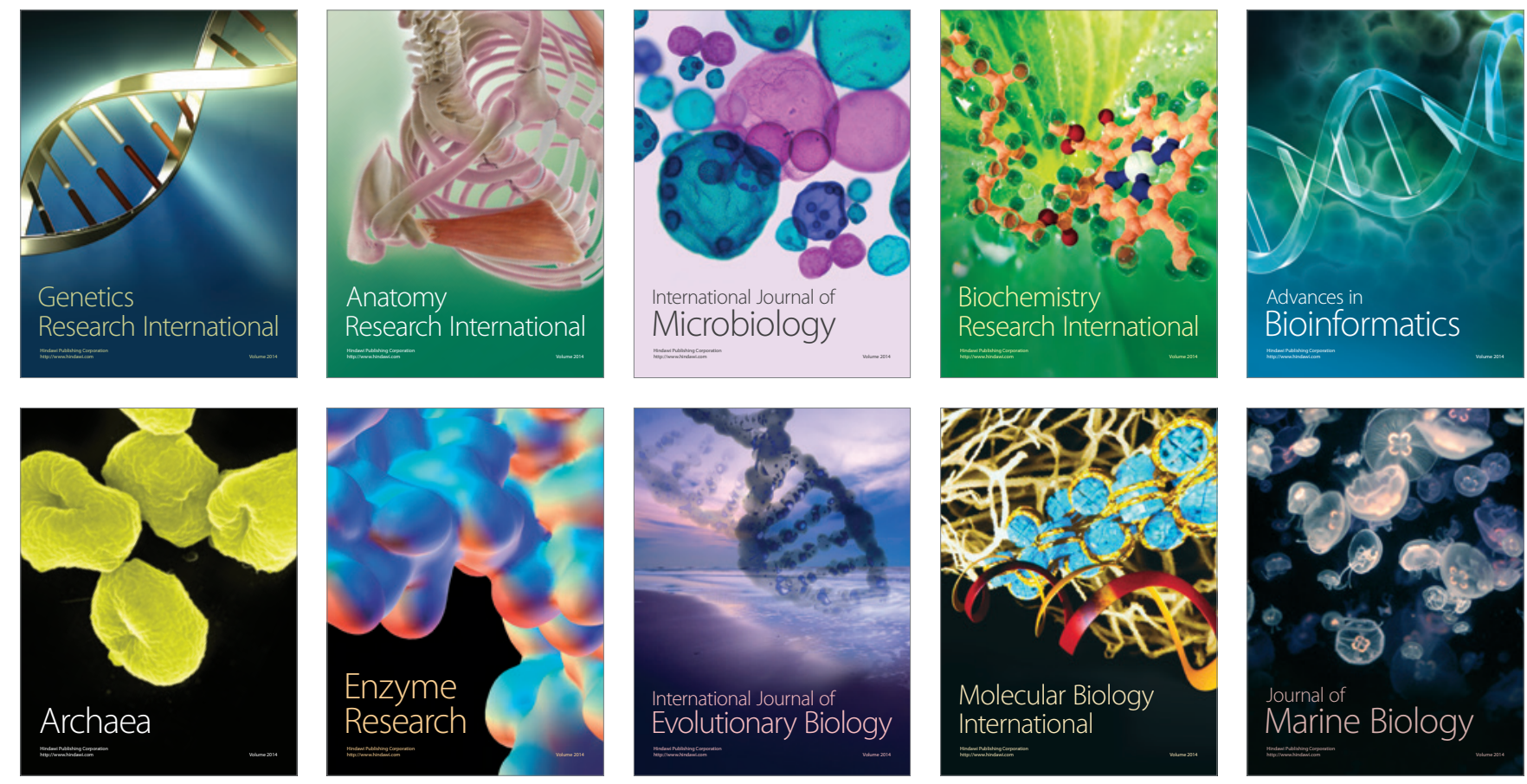